This is an Author's Accepted Manuscript of an article published in

Journal Title: Studies in Higher Education

Article title: The need to disentangle assessment and feedback in higher education

Authors: Winstone, N. E.; Boud, D.

Pagination

Online publication date 01 Jan 2021

Copyright is held by Taylor and Francis. 
Accepted version of Winstone, N.E. \& Boud, D. (accepted for publication, 31 May 2020). The need to disentangle assessment and feedback in higher education, Studies in Higher Education, DOI: 10.1080/03075079.2020.1779687

\title{
The need to disentangle assessment and feedback in higher education
}

\author{
Naomi E. Winstone ${ }^{1}$ and David Boud ${ }^{2,3,4}$ \\ ${ }^{1}$ Department of Higher Education, University of Surrey, Guildford, UK \\ ORCID: 0000-0001-8157-8274 \\ @DocWinstone@SurreyLab \\ ${ }^{2}$ Centre for Research in Assessment and Digital Learning, Deakin University, Melbourne, \\ Australia \\ ${ }^{3}$ Faculty of Arts and Social Sciences, University of Technology Sydney, Australia \\ ${ }^{4}$ Centre for Research on Work and Learning, Middlesex University, London, UK \\ ORCID: 0000-0002-6883-2722
}

\begin{abstract}
In contemporary higher education systems, the processes of assessment and feedback are often seen as coexisting activities. As a result, they have become entangled in both policy and practice, resulting in a conceptual and practical blurring of their unique purposes. In this paper, we present a critical examination of the issues created by the entanglement of assessment and feedback, arguing that it is important to ensure that the legitimate purposes of both feedback and assessment are not compromised by inappropriate conflation of the two. We situate our argument in the shifting conceptual landscape of feedback, where there is increasing emphasis on students being active players in feedback processes working with and applying information from others to future learning tasks, rather than regarding feedback as a mechanism of transmission of information by teachers. We surface and critically discuss six problems created by the entanglement of assessment and feedback: students' focus on grades; comments justifying grades rather than support learning; feedback too late to be useful; feedback subordinated to all other processes in course design; overemphasis on documentation of feedback; and the downgrading of feedback created by requirements for anonymous marking. We then propose a series of strategies for preserving the learning function of feedback, through models that give primacy to feedback within learning cycles. We conclude by offering suggestions for research and practice that seek to engage with the challenges created by the entanglement of assessment and feedback, and that maintain the unique purposes of assessment and feedback.
\end{abstract}

Keywords: Assessment; Feedback; Summative; Formative; Students 


\title{
The need to disentangle assessment and feedback in higher education
}

\author{
Grades often tell the student 'the work is over'. We must not confuse \\ grading with feedback. (Hattie and Clarke 2019,2)
}

The marking or grading of student work and the provision of feedback comments are some of the most common undertakings within universities internationally. The term 'assessment and feedback' forms a conjunction of activities that often go hand-in-hand: whenever assessment of learning takes place, feedback information should be provided to students, leading feedback to be 'intimately linked with marking' (Chalmers et al. 2018, 37). This is seen, for example, in the fact that the effectiveness of assessment and feedback in university courses is often assessed as a single entity (e.g. in the UK National Student Survey and the Australian Course Experience Questionnaire). This conglomeration of assessment and feedback has left us with a problem. Whilst both assessment and feedback have important and legitimate roles in university courses, they do not have the same function. However, the ways in which they have become entangled in policy and practice have resulted in a conceptual and practical blurring of their unique purposes. In this paper, we present a critical examination of issues created by the entanglement of assessment and feedback, arguing that it is important to ensure that the legitimate purposes of both feedback and assessment are not compromised by inappropriate conflation of the two.

Assessment is primarily seen as serving an evaluation and certification function. Whilst the process of undertaking a task can be a valuable learning opportunity in itself (e.g. Boud and Soler 2016), assessment commonly focuses on summative evaluation of student performance against appropriate standards or criteria, in order to generate grades which are reliable, valid, and defensible. On the other hand, the primary function of feedback is to influence students' future work and learning strategies. Thus, within the same act of grading work and providing comments, the marker is enacting two very different purposes: grade award and justification (considering past achievement) and the provision of feedback information (to influence future achievement).

We recognise that both of these functions are important. However, the way in which assessment processes are organised can mean that the two purposes are conflicting, in such a way that the dominance of assessment inhibits the purposes of feedback. Whilst the same task can result in the occurrence of both assessment and feedback, we need to pay attention to the potential for the purposes to interfere with one another. Currently, we suggest, assessment often 'strangles' the learning function of feedback. We need to reposition feedback as more than an afterthought, to something that is meaningful in its own right, not just something that happens alongside assessment.

\section{Feedback and the functions of formative and summative assessment}

The issues we have discussed thus far echo similar conversations about the relationship between the formative and summative functions of assessment. Following Scriven's (1967) distinction between the formative and summative functions of evaluation, there has been considerable debate over the unique functions of each. Summative assessment functions typically represent judgements of learning that has taken place, with formative functions reserved for instances where the process informs learning as it is progressing. Whilst the process of formative assessment also involves an informal process of judgement, purists would argue that 'The purpose [of formative observations] is not to grade or certify the learner; it is to help both the learner and the teacher focus upon the particular learning necessary for movement towards mastery' (Bloom et al. 1971, 61). 
The overlapping and sometimes contested functions of formative and summative assessment are described by Cookson $(2018,930)$ as a 'conceptual mêlée', reflecting the lack of clarity over nomenclature. Similarly, Rand (2017) argues that the dichotomy between formative and summative functions of assessment is a simplistic one, whilst Black $(1998,34)$ states that 'the two functions are two ends of the same spectrum'. Sadler (1989) argued against the same assessment task serving both a formative and summative purpose, for the reason that the grade or mark (a summative evaluation) might obscure students' attention to the formative purpose of feedback information. Taking this argument further, Rust (2000) advocated removing summative assessment from modules; instead, he proposed that modulebased learning should be purely formative in function, with summative assessment taking place at a programmatic level. It becomes clear that in many cases formative assessment is merely a summative assessment with the addition of some feedback information (Taras 2005). This indicates the primacy of assessment, with feedback serving as an adjunct to the dominant purpose of summative grading. However, if feedback purely serves as grade justification, then arguably there is limited formative function even to the feedback element (Brown and Glover 2006).

\section{Defining feedback}

There is a very broad literature on the topic of feedback, with multiple perspectives and many different uses of the term. For the purposes of this paper, we define feedback as 'processes where the learner makes sense of performance-relevant information to promote their learning' (Henderson et al. 2019a, 15). In this sense, feedback is not about grade justification but forward-looking information that helps students further develop their work.

Arguments about the problems associated with feedback processes in higher education are well-rehearsed elsewhere (e.g., Henderson et al. 2019b), and we do not repeat those arguments here. Nevertheless, we acknowledge that feedback practices as they are commonly enacted create problems in terms of student satisfaction, student engagement, and staff workload, meaning that for both educators and students, feedback processes are often neither productive nor satisfying. Increasingly evident in the literature is an appreciation that moving beyond this impasse requires a conceptual and practical reframing of feedback away from a process driven by teachers, towards a learning-focused process where students are active players in feedback processes who work with and apply information from others to future learning tasks (e.g., Boud and Molloy 2013; Price et al. 2011). However, the entanglement of assessment and feedback can impede this shift towards learning-focused feedback processes. In particular, a learning-focused approach requires feedback processes to come to the fore within assessment regimes, while the dominant assessment and feedback culture in current practice runs counter to this approach (Winstone and Carless 2019).

\section{Exploring entanglement}

We were prompted to explore the issue of entanglement as the result of recent projects in which we have been involved, exploring influences on feedback processes at the levels of units, courses, and programmes, in different countries and contexts. The 'Feedback Cultures in Higher Education' project involved a survey administered to UK academics, with comparable data taken from an earlier study in Australia. It focused on exploring common approaches to feedback processes, and influences on design decisions; one part of the survey involved respondents completing a series of open-ended questions. These involved: 1) defining the feedback process in their own words; 2) describing what makes for 'effective' feedback; 3) and outlining how they would know whether their feedback had been effective. Detailed findings are reported in Winstone and Boud (2019). 
The project also involved semi-structured interviews with a) 28 academics, and b) three senior leaders in learning and teaching. The former focused on understanding influences on feedback designs, in particular, the roles of quality assurance and accountability. The latter aimed to uncover the challenges experienced in feedback processes at the level of programmes and courses, rather than individual modules or units.

The final strand consisted of an evidence synthesis and collation of example feedback designs (Winstone and Carless 2019). The current paper was inspired by a meta-level understanding gleaned through synthesis of all elements of the projects. It became apparent through data memos that a common source of dissonance in practice was the often troublesome entanglement of the grading and development functions of assessment cycles in higher education. The paper is structured as follows. First, we identify ways in which assessment and feedback are commonly entangled, and the problems thus created, illustrated through the voices of our project participants. We then discuss potential strategies to avoid challenges created by the co-location of assessment and feedback, supported by relevant literature.

\title{
The challenges created by entanglement
}

\section{Students focus on grades rather than developmental information}

\author{
I do all this writing, they don't read it, they just look at the number, so why \\ am I wasting my time? \\ (Senior Leader Interview, Arts)
}

This quotation from a Director of Learning and Teaching represents a common frustration experienced and reported by academic staff: they provide detailed written comments alongside grades on students' work, but students appear to be most interested in the grade, often disregarding the feedback (Duncan 2007). This is a loss of information that is potentially valuable for students' learning and results in time wasted by academics. Students themselves report that they are primarily interested in grades rather than feedback (e.g. Rand 2017; Winstone et al. 2017a), and academic staff often perceive students to ignore comments once they have sight of the grade (e.g. Bailey and Garner 2010). Similar findings emerge in online learning environments. For example, Mensink and King (2020) analysed the extent to which students accessed electronic files containing feedback comments in a Learning Management System. The authors found that when grades were visible to students without opening the accompanying feedback file, $42 \%$ of feedback files were not accessed. In contrast, when students' grades were presented within the feedback file, meaning that they could not see their grade without opening the feedback file, the rate of non-access fell to just $17 \%$. Whilst the authors acknowledge that opening the feedback file does not equate to meaningful engagement with its contents, this study clearly demonstrates that if grades are easily accessible, feedback information may well be ignored.

But might the trope of 'students are not interested in feedback, only grades' in part be an artefact of the co-location of grades and feedback information? Whilst students report interest in grades, they also express a hunger for feedback information (e.g. Higgins et al. 2002; Winstone et al. 2016). Thus, limited focus on feedback information when accompanying a grade may be an attentional, affective, and motivational by-product of the entanglement of assessment and feedback.

Not only do grades and feedback information serve different purposes, students have different motivations to engage with each. In a seminal study with child participants, Butler (1988) demonstrated that feedback comments are more likely to be forgotten if presented 
alongside grades rather than in isolation. Butler argues that grades capture attention because they provide ego-involving normative information, with a motivational effect on maintaining self-worth. Instead, feedback comments promote task-involved motivation, encouraging mastery. The impact of the normative information contained within grades on self-worth are illustrated by evidence regarding the emotional impact of grades on students' subsequent engagement with feedback (e.g. Orsmond et al. 2005; Jones et al. 2012). For example, students in a study by Gomez and Osborne (2007) reported that when receiving a low grade, they found it too emotionally uncomfortable to read the feedback. In contrast, students who received a high grade, resulting in satisfaction, perceived the feedback as unnecessary. Similarly, Rand (2017) described similar behaviour:

Overwhelmingly, students reported locating their grade (at the bottom of the form) before reading the written comments. Most students reviewed the written comments as a secondary activity, although many reported never reading the written comments, and often students reported delaying reading the comments particularly if they perceived the grade as 'bad'. (Rand 2017, 41)

It is also important to consider whether there is a de facto message being transmitted to students by the conjunction of grades and feedback. When grades are seen as the primary emphasis, then feedback comments may be viewed as an accompanying or supporting narrative, rather than conveying important developmental information in their own right. There is clear evidence that when presented alongside grades, feedback information will occupy second place, potentially becoming obscured by students' hunger for normative performance information.

\title{
Teachers focus comments on justifying the grade rather than providing developmental information
}

\author{
While [feedback] should be about helping students maximise their learning \\ experience, these days it is a kind of backside-covering exercise to avoid \\ student complaints - lecturers have to justify their mark to avoid a challenge \\ rather than focussing on student learning. \\ (Survey response, definition of feedback)
}

This response from an academic as they defined feedback indicates that quality assurance mechanisms are a prevalent influence on feedback processes. Where feedback accompanies a grade, it is common for the style of feedback comments to more closely reflect the justification of a grade than the provision of developmental information. Indeed, teachers find it challenging to balance grade justification and supporting development in their framing of feedback comments (Li and Di Luca 2014). Furthermore, some teachers report focusing on the accountability function of feedback at the expense of dialogue with students, in part to protect themselves from student complaints (Tuck 2017). This challenge arises from the dual and conflicting purposes of assessment and feedback, where the purpose of assessment (to provide transparent and defensible grading of student work) has the potential to influence the way in which feedback information is framed.

Where feedback comments take on the flavour of grade justification, there is potential to limit student learning for several reasons. First, grade justification follows a retrospective emphasis that looks back on what a student has done, rather than serving to facilitate improvement that looks to what a student could do to produce better work in the future. Second, whilst an emphasis on grade justification can be seen to enhance transparency, it often inadvertently reduces transparency of the feedback information itself. The literature 
contains numerous reports of academic 'jargon' in feedback comments causing confusion for students (see, for example, Jönsson 2013; Winstone, et al. 2017a). Given that grade justification is likely to reflect the language of formal grading policies and grade descriptors, this may increase the opacity of feedback information. Third, an emphasis on grade justification in feedback goes against what both teachers and students view as the primary purpose of feedback. For example, in a recent large-scale survey study involving teachers and students in Australian universities (Dawson et al. 2019), 89\% of teachers and 90\% of students expressed a belief that the purpose of feedback is to facilitate improvement. In stark contrast, only $7 \%$ of teachers and $4 \%$ of students believed grade justification to be the purpose of feedback. While the information required for feedback purposes can be combined with explanations as to why a particular grade was achieved, they each have a different focus. While they begin at a common starting point — the student's work - they rapidly diverge in different directions from what has been done, to what can be done.

\title{
Feedback information can come too late to be of use
}

\author{
[Feedback] should allow students to reflect on their work and use this to \\ feed forward to the next assessment. However this can be difficult in a \\ modular degree.
}

(Survey response, definition of feedback)

This participant, in responding to a request to define the feedback process, made reference to the challenges created by modular degree courses (that is, those programmes divided into self-contained units not directly linked to other units) and the timing of assessment and feedback processes. This response reflects concerns, well-represented in the literature, that feedback information does not come in time to be of use in informing students' subsequent work (e.g. Higgins et al. 2001; Jönsson 2013).

There are often contextual constraints on the timing of assessment tasks, resulting from factors such as the length of semesters, staff availability, the timing of examination boards, and programme-level assessment structures. If feedback information is something that accompanies grading, then these constraints also apply to the timing of feedback processes.

Co-locating grading and feedback also means that feedback accompanies the grade through the quality assurance chain of internal moderation/second marking, because of the stakes assigned to grades and the consequential need to ensure that they are defensible. Whilst moderation processes are likely to differ between countries, in the UK context Bloxham (2009) identifies that such processes increase the time taken to return work to students. This becomes problematic given further evidence that where students have to wait a long time for feedback information on their work, their engagement with that information is limited (Nicol and Macfarlane- Dick 2006; Yang and Carless 2013). This can mean that by the time students have the opportunity to engage with feedback information, it is too late for that information to inform their ongoing learning, as they have already completed a subsequent task or they are unable to apply it to work-in-progress. In a focus group study by Poulos and Mahony (2008), students reported that feedback on assignments that occur towards the end of a module is perceived as irrelevant, as there is no opportunity for them to enact the advice. Similarly, in their analysis of student engagement with feedback files in Learning Management Systems, Mensink and King (2020) reported that feedback files pertaining to assessment tasks earlier in the semester were more likely to be accessed than those pertaining to assessment tasks later in the semester. Thus, the temporal location of feedback events can often unwittingly position students as passive recipients of information, 
with limited agency to take action (Carless et al. 2011). In many cases, comments may be of most use prior to the submission of graded work (Boud and Molloy 2013; Gibbs and Simpson 2004). However, where feedback is entangled with grading, this option is often not considered.

\section{Feedback is not a focus in course design}

It would be nice to be able to specifically design follow up assessment tasks to allow students to enact the feedback comments they receive in prior tasks, but for administrative/audit purposes, our institution very tightly constrains the way in which we assess.

(Survey response, what makes effective feedback)

In their response to the question of what makes effective feedback, this participant expressed frustration surrounding the perceived constraints on their capacity to design feedback processes such that the enactment of comments is built into the cycle. In assessment design at the level of the module or unit, perhaps the most common questions informing design are 1) what is the purpose of the assessment task?; 2) what is the assessment task going to be?; and 3) when will it be submitted by and returned to students? These decisions are often required to be confirmed far in advance of the actual running of the unit. Thus, with many assessments to fit into a teaching block, assessment takes priority in terms of design, with feedback subordinate to assessment in design terms. In the recent literature, there have been renewed calls for the importance of feedback having a design focus in its own right, beyond simply following on from however assessment has been designed (Boud and Molloy 2013; Henderson et al. 2019a; Winstone and Carless 2019). This entails consideration of where feedback best fits within learning cycles, and what form that feedback process may take. Esterhazy et al. $(2019,4)$ characterise 'feedback opportunities' as 'those potential encounters incorporated within course designs in which students might seek, generate, or make use of information about the quality of their work' . Crucially, they argue that 'educators must create opportunities for students to enter into dialogues with their teachers and peers, and access resources that will support their understanding' (Esterhazy et al. 2019, 2). In this vein, it becomes clear that focusing in design terms on the nature of an assessment task and the timescale for its submission, grading, and return does not provide space for thinking about where 'feedback opportunities' will be embedded within the process.

\section{Forms of documenting feedback can impair its quality}

[Academics] talk ... very positively about the actual work, even just in the critique of the work, 'it was okay, but this needs...' and it's full of passion and drive. That all disappears when it comes to sitting at the computer and writing up the report. And then it becomes, you know... for want of a better phrase, 'these bloody reports'!

(Senior Leader Interview, Arts)

When discussing the experiences of their department with regard to feedback processes, this leader described how the pleasure they might experience in supporting students' development through feedback can be diluted when it comes to formally documenting feedback within a proforma or template. It appears that the very process of documenting feedback information in a prescribed way changes the nature of communication; what would naturally be informal, personal, and developmental, can become formal, official, and driven by a different agenda. 
When feedback accompanies a formal assessment event, there can be a concomitant focus on documenting feedback, which then raises the question of whether the feedback serves an accountability function, or serves to support student learning. There is a strong focus on form-filling and the creation of feedback artefacts in practice, but also in definitions of feedback, where it is seen as '...information given [often] using pre-designed rating schedules, forms or "score sheets" that might contain a tick in a box against a particular criterion or characteristic to indicate whether the work being assessed has that attribute' (Jolly and Boud 2013, 105).

An accountability focus on documenting feedback can accentuate a transmission view of comments, where attempts to improve feedback processes focus on tinkering with the nature of the presentation of information within documentation, rather than focusing on supporting students to become more active in feedback processes (Nash and Winstone 2017). The documentation of feedback in standard templates can also send implicit messages to students about the ways in which their teachers value feedback. In their systematic review of students' engagement with feedback, Winstone et al. (2017b) argued that whilst such artefacts can have a positive impact on academic workload, they can be perceived by students as implying that their markers wish to reduce the effort in feedback, which in turn can lead to learners' lack of engagement with feedback (Price et al. 2011). In contrast, the use of audio, video, and screencast feedback have the potential to create more authentic dialogues free from the constraints of standard templates with the added advantage of reducing academic workload (e.g. Mahoney et al. 2019).

\title{
Anonymous grading depersonalises and inhibits the quality of feedback
}

\author{
Work is marked anonymously, so how can the comments be made \\ personal to a given individual? \\ (Survey response, what makes effective feedback)
}

This respondent echoes a key challenge represented in the literature that directly results from the entanglement of assessment and feedback. The assessment policies of many higher education institutions require student work to be graded anonymously, in order to protect students from unconscious bias, on the basis of suggestions that knowing the identity of student can lead to the influence of unconscious bias on grading decisions (e.g. Malouff and Thorsteinsson 2016). In contrast, some evidence suggests that anonymous marking has little impact on differential student attainment (e.g., Hinton and Higson 2017; Pitt and Winstone 2018). However, when feedback accompanies grades, comments automatically become anonymous, potentially creating barriers to student learning.

On a very basic level, the practice of anonymous grading can reduce the likelihood of feedback occurring at all, at least on a formative basis. If students have been able to engage with comments on a draft assignment, there is a perception that the grading of the final piece will be compromised in terms of anonymity, which can be perceived as a barrier to the implementation of formative feedback (Orsmond et al. 2005). In summative assessment, anonymous grading seriously limits the potential for individualised comments that complete feedback loops (Whitelegg 2002), and may position students as passive receivers in a monologic feedback process (Pitt and Winstone 2018). The ipsative function of feedback, where markers can directly comment not on absolute performance, but on progression in relation to the previous assessment (e.g. Hughes 2011), is also compromised. In a recent study of anonymous grading, Pitt and Winstone (2018) reported that in contrast to anonymous marking, students perceived feedback on non-anonymous work as more useful, as it is able to reference prior work and attend to the particular needs or priorities of the 
student. Furthermore, students perceived a stronger relationship with their lecturers where work was marked non-anonymously. Price et al. (2010) argue that non-anonymous grading is more relational than anonymous grading, so dialogue and the development of working alliances between teachers and students may be compromised by anonymous grading practices. This is an area in which there are striking tensions between the needs of gradingneeding anonymity to reduce bias - and that of feedback, where information about individual progression results in more meaningful advice.

\section{Strategies for preserving the learning function of feedback}

In this section we identify particular strategies that might mitigate some of the problems created by entanglement, especially between grades or marks on the one hand and feedback processes on the other (Figure 1). While an obvious strategy would be to disentangle completely and separate tasks that are graded from those that only involve feedback, this can be difficult to implement in some course units as they may be too short to accommodate the reduction of summative assessment that would necessarily need to occur. It would also be a problem if preceding units had established a cultural expectation in students that all tasks would be graded.

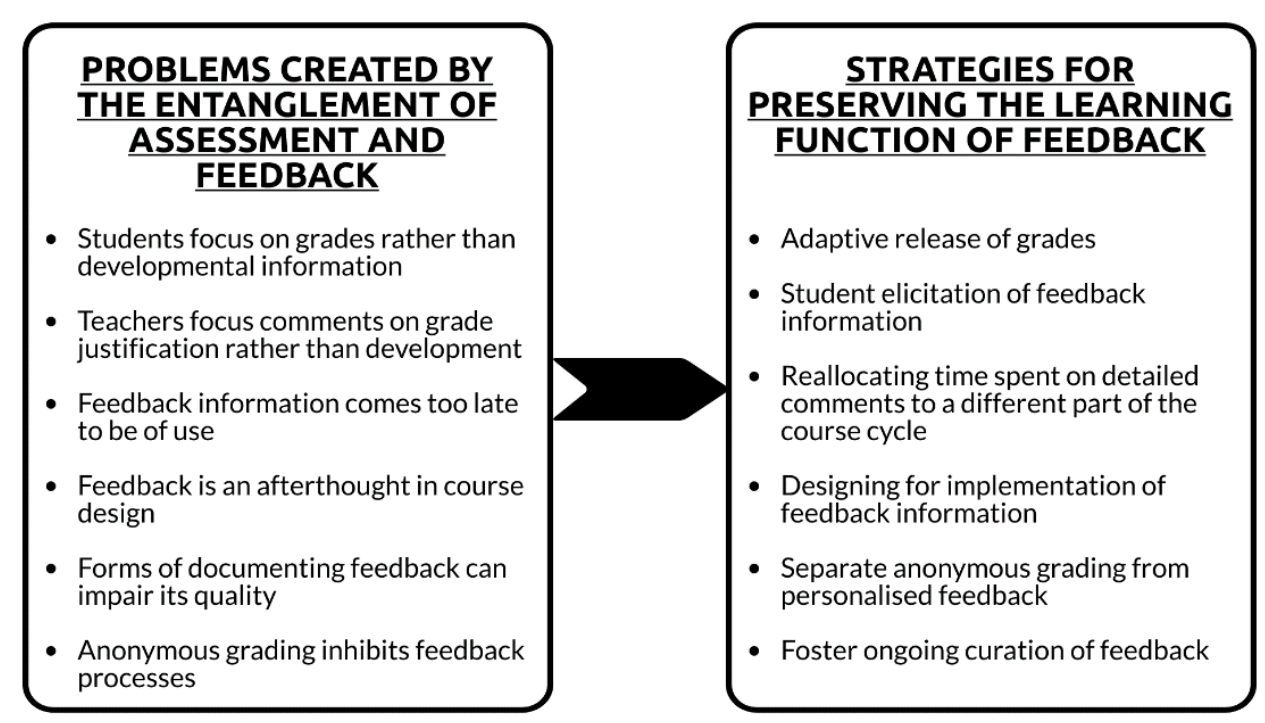

Figure 1. Summary of problems created by and solutions to the entanglement of assessment and feedback

\section{Adaptive release of grades}

Where grades can distract students from engagement with potentially useful feedback information, then withholding grades until students have engaged with feedback information, sometimes called 'adaptive release of grades', is a potential solution (e.g. Parkin et al. 2012). Whilst students may express anxiety about receiving comments in the absence of a quantitative indication of how they have performed on the task (e.g. Parker and Winstone 2016), some evidence suggests that students may be more likely to engage with developmental feedback information if received in advance of a summative grade (e.g. Sendziuk 2010; Jackson and Marks 2016). The strategy is to deemphasise the grade by enhancing the formative features of the task. 


\section{Student elicitation of feedback information}

Students' attention to feedback information rather than grades might be promoted by positioning students as initiators of a feedback dialogue in which they have declared a stake, rather than as recipients of unsolicited information. The importance of students eliciting comments on their work rather than passively awaiting receipt of them has been identified as a key feature of feedback literacy (Molloy et al. 2019). The simplest way in which this can be done is through an interactive cover sheet, where students identify how they have used feedback from prior tasks to inform the current submission, and can request comments on particular aspects of their work (e.g. Bloxham and Campbell 2010). This requires some orientation as inexperienced students may be tempted to write 'everything' rather than take the time to ponder what they believe they need. A potential mitigation is to have students make an appraisal of their own work which they submit before grades and feedback information are released. They are thus primed to look to confirm or disconfirm their own judgement and receive information on how that might be calibrated (Boud et al. 2015). This involves the provision of feedback information about students' judgements of their work rather than on the substantive work itself. The latter is only provided when students' judgement is wanting.

\section{Designing for implementing feedback information}

Any intermediate assessment task should be regarded not as a discrete activity undertaken at a particular point of time, but as part of a necessary ongoing learning process which involves students acting in anticipation of the task, during the task and following receipt of information about their performance of the task. This can be made explicit through activities which ask students how they are going to incorporate feedback information from previous tasks in current tasks and ask them to report on what they take forward from feedback on the current task into what they will do next (Henderson et al. 2019a). An alternative design strategy is to create nested or sequenced tasks across a semester. These may either break down the final product into stages or establish opportunities for students to receive information on drafts as a necessary part of the overall assessment process. Such a sequencing can maximise the chances for students to see that feedback information has an immediate use and for them to put a response into practice in a timely fashion, that is, prior to submission of the next stage of the task.

\section{Reallocating time spent on providing detailed comments to a different part of the learning cycle}

It is common for a large part of the time devoted by teachers to feedback activities to be delivered at the times of the year when students are least receptive to it and have the least opportunities to act on it. That is, at the end of the semester or academic year. It is quite proper for the justification of marks to occur at times such as this as these occasions are when assessment for the assurance of learning is needed. However, they are not auspicious times for the delivery of future-oriented feedback information unless course units are extremely well aligned programmatically to allow for students to utilise feedback information in the following semester. Depending on the specific requirements of individual disciplines, it may be possible to decouple feedback from grading by providing detailed comments on work-inprogress, and giving students the opportunity to apply them to a final graded task. Students are enabled to implement comments, and the time of academic staff would be used to greater effect. 


\section{Separate anonymous grading from personalised feedback}

It could be argued that the negative impact of anonymous grading on the learning potential of feedback occurs purely because assessment and feedback are entangled. Just because work is graded anonymously does not mean that feedback comments also need to be provided without knowing the identity of the student. Whitelegg (2002) recommended that tutors grade work anonymously, and then subsequently unmask the work so that it is possible to direct comments to students on an individual basis, commenting on progress and learning goals. This is important if the relational and dialogic functions of feedback are to be preserved (Pitt and Winstone 2018). The practicalities of enacting this approach are likely to differ according to the specific tools used for grading and feedback in any given context; however, the basic principle remains the same.

\section{Foster ongoing curation of feedback}

Greater emphasis on the developmental function of feedback can be achieved through systems that support the collation and synthesis of feedback, such as a feedback portfolio (Clarke and Boud 2018; Winstone 2019). For students, this enables them to track their development in relation to prior feedback information, and identify what they need to address in future work. For tutors, this enables them to build on and not simply repeat comments which have not been acted upon. If it is expected that students will work with and process the feedback information they receive, then LMSs need to be configured to enable this. This could be achieved through digital curation of feedback in e-portfolios, where feedback comments could be retrieved by topic or by related learning outcome. Ongoing curation of feedback is also important to position the purpose of feedback as more than just improvement in numerical performance. Tracking the impact of feedback could enable students to recognise the influence of feedback processes on key outcomes such as confidence, skills, self-concept, and employability (Winstone 2019).

\section{Disentanglement: Implications for research and practice}

We have drawn upon the voices of participants in our projects to open up a critical dialogue about the ritualised nature of feedback as it is often practised in higher education. Feedback practices in higher education have remained stubbornly similar and habitual for far too long, and things do not have to be this way. We have called for renewed focus on the distinct functions of assessment and feedback, to ensure that each can be properly met, rather than ignoring the fact that one is likely to be obscuring the other.

Such a focus might encourage researchers to look for the potential impact of entanglement within their research, and design ways of examining each unique function. We recognise that our argument draws upon data collected from Australia and the UK; exploring issues of the entanglement of assessment and feedback in other national contexts is an important direction for further research. In terms of practice, disentanglement requires feedback to be designed into courses, rather than focusing on assessment designs alone where the feedback function may be compromised from the start. Disentangling the functions of assessment and feedback also requires acknowledgment that only limited progress can be made by focusing on individual course units. A programmatic view needs to be taken of both assessment and feedback. Finally, in order for the unique functions of assessment and feedback to be preserved, tutors and students need to engage in dialogue about the importance of these functions, and to agree how feedback will support learning in a unit or programme. Attempts to disentangle assessment and feedback are likely to have limited impact if students are unaware of how and why their tutors have designed feedback for learning into their learning, teaching, and assessment activities. 


\section{Acknowledgement}

The research reported in this paper was supported by the Society for Research into Higher Education through the award of a research grant (RA1648).

\section{References}

Bailey, R., and M. Garner. 2010. "Is the feedback in higher education assessment worth the paper it is written on? Teachers' reflections on their practices". Teaching in Higher Education 15(2): 187-198.

Black, P.J. 1998. Testing: Friend or Foe? The Theory and Practice of Assessment and Testing. London: Falmer Press.

Bloom, B.S., T.J. Hastings, and G.F. Madaus. 1971. Handbook on formative and summative evaluation. New York: McGraw-Hill.

Bloxham, S. 2009. "Marking and moderation in the UK: false assumptions and wasted resources". Assessment and Evaluation in Higher Education 34(2): 209-220.

Bloxham, S., and L. Campbell. 2010. "Generating dialogue in assessment feedback: Exploring the use of interactive cover sheets". Assessment and Evaluation in Higher Education 35(3): 291-300.

Boud, D., R. Lawson, and D.G. Thompson. 2015. "The calibration of student judgement through self-assessment: disruptive effects of assessment patterns". Higher Education Research and Development 34(1): 45-59.

Boud, D., and E. Molloy. 2013. "Rethinking models of feedback for learning: the challenge of design". Assessment and Evaluation in Higher Education 38(6): 698-712.

Boud, D., and R. Soler. 2016. Sustainable assessment revisited. Assessment and Evaluation in Higher Education 41(3): 400-413.

Brown, E., and C. Glover. 2006. "Evaluating written feedback". In Innovative assessment in higher education, edited by C. Bryan and K. Clegg, 101-111. Abingdon: Routledge.

Butler, R. 1988. "Enhancing and undermining intrinsic motivation: The effects of taskinvolving and ego-involving evaluation on interest and performance". British Journal of Educational Psychology 58(1): 1-14.

Carless, D., D. Salter, M. Yang, and J. Lam. 2011. "Developing sustainable feedback practices". Studies in Higher Education 36(4): 395-407.

Chalmers, C., E. Mowat, and M. Chapman. 2018. "Marking and providing feedback face-toface: Staff and student perspectives". Active Learning in Higher Education, 19(1): 3545.

Clarke, J. L., and D. Boud. 2018. "Refocusing portfolio assessment: Curating for feedback and portrayal". Innovations in Education and Teaching Internationa, 55(4): 479-486.

Cookson, C. J. 2018. "Assessment terms half a century in the making and unmaking: from conceptual ingenuity to definitional anarchy". Assessment and Evaluation in Higher Education 43(6): 930-942.

Dawson, P., M. Henderson, P. Mahoney, M. Phillips, T. Ryan, D. Boud, and E. Molloy. 2019. "What makes for effective feedback: Staff and student perspectives". Assessment and Evaluation in Higher Education 44(1): 25-36.

Duncan, N. 2007. "“Feed-forward': improving students' use of tutors' comments". Assessment and Evaluation in Higher Education 32(3): 271-283.

Esterhazy, R., M. Nerland, and C. Damşa. 2019. "Designing for productive feedback: an analysis of two undergraduate courses in biology and engineering". Teaching in Higher Education, Advance Online Publication.

Gibbs, G., and C. Simpson. 2004. "Does your assessment support your students' learning?". Journal of Teaching and Learning in Higher Education 1(1): 1-30. 
Gomez, S., and R. Osborne. 2007. "Enhancing student appreciation of written feedback on essay assignments". In Enhancing teaching and learning through assessment: Deriving an appropriate model, edited by S. Frankland, 40-50. Dordrecht: Springer.

Hattie, J., and S. Clarke. 2018. Visible Learning: Feedback. Abingdon: Routledge.

Henderson, M., E. Molloy, R. Ajjawi, and D. Boud. 2019a. "Designing feedback for impact". In The Impact of Feedback in Higher Education, edited by M. Henderson, R. Ajjawi,D. Boud, and E. Molloy, 267-285. London: Palgrave Macmillan.

Henderson, M., T. Ryan, and M. Phillips. 2019b. "The challenges of feedback in higher education". Assessment and Evaluation in Higher Education 44(8): 1237-1252.

Higgins, R., P. Hartley, and A. Skelton. 2001. "Getting the message across: the problem of communicating assessment feedback". Teaching In Higher Education 6(2): 269-274.

Higgins, R., P. Hartley, and A. Skelton. 2002. "The conscientious consumer: Reconsidering the role of assessment feedback in student learning". Studies in Higher Education 27(1): 53-64.

Hinton, D. P., and H. Higson. 2017. "A large-scale examination of the effectiveness of anonymous marking in reducing group performance differences in higher education assessment". PloS one, 12(8).

Hughes, G. 2011. "Towards a personal best: A case for introducing ipsative assessment in higher education". Studies in Higher Education 36(3): 353-367.

Jackson, M., and L. Marks. 2016. "Improving the effectiveness of feedback by use of assessed reflections and withholding of grades". Assessment and Evaluation in Higher Education 41(4): 532-547.

Jolly, B., and D. Boud. 2013. "Written feedback: What is it good for and how can we do it well?". In Feedback in higher and professional education, edited by D. Boud and E. Molloy, 104-124. Abingdon: Routledge.

Jones, N., P. Georghiades, and J. Gunson. 2012. "Student feedback via screen capture digital video: Stimulating student's modified action". Higher Education 64(5): 593-607.

Jönsson, A. 2013. "Facilitating productive use of feedback in higher education". Active Learning in Higher Education 14(1): 63-76.

Li, J., and R. De Luca. 2014. "Review of assessment feedback". Studies in Higher Education 39(2): 378-393.

Mahoney, P., S. Macfarlane, and R. Ajjawi. 2019. “A qualitative synthesis of video feedback in higher education". Teaching in Higher Education 24(2): 157-179.

Malouff, J. M., and E.B.Thorsteinsson. 2016. "Bias in grading: A meta-analysis of experimental research findings". Australian Journal of Education, 60(3): 245-256.

Rand, J. 2017. "Misunderstandings and mismatches: The collective disillusionment of written summative assessment feedback". Research in Education, 97(1): 33-48.

Mensink, P.J., and K. King. 2020. Student access of online feedback is modified by the availability of assessment marks, gender and academic performance. British Journal of Educational Technology 51(1): 10-22.

Molloy, E., D. Boud, and M. Henderson. 2019. "Developing a learning-centred framework for feedback literacy". Assessment and Evaluation in Higher Education, Advance Online Publication. DOI: 10.1080/02602938.2019.1667955

Nash, R.A., \& N.E. Winstone. 2017. "Responsibility-sharing in the giving and receiving of assessment feedback". Frontiers in Psychology 8, 1519.

Nicol, D.J., and D. Macfarlane-Dick. 2006. "Formative assessment and self-regulated learning: A model and seven principles of good feedback practice". Studies in Higher Education 31(2): 199-218. 
Orsmond, P., S. Merry, and K. Reiling. 2005. "Biology students' utilization of tutors' formative feedback: a qualitative interview study". Assessment and Evaluation in Higher Education 30(4): 369-386.

Parker, M., and N.E. Winstone. 2016. "Students' perceptions of interventions for supporting their engagement with feedback". Practitioner Research in Higher Education 10(1): 53-64.

Parkin, H.J., S. Hepplestone, G. Holden, B. Irwin, and L. Thorpe. 2012. “A role for technology in enhancing students' engagement with feedback". Assessment and Evaluation in Higher Education 37(8): 963-973.

Pitt, E., and N. Winstone. 2018. "The impact of anonymous marking on students' perceptions of fairness, feedback and relationships with lecturers". Assessment and\& Evaluation in Higher Education 43(7): 1183-1193.

Poulos, A., and M.J. Mahony. 2008. "Effectiveness of feedback: The students' perspective". Assessment and Evaluation in Higher Education 33(2): 143-154.

Price, M., K. Handley, J. Millar, and B. O'Donovan. 2010. "Feedback: all that effort, but what is the effect?" Assessment and Evaluation in Higher Education 35(3): 277-289.

Price, M., K. Handley, and J. Millar. 2011. "Feedback: Focusing attention on engagement". Studies in Higher Education 36(8): 879-896.

Rust, C. 2000. "An opinion piece: A possible student-centred assessment solution to some of the current problems of modular degree programmes". Active Learning in Higher Education,1(2), 126-131.

Sadler, D.R. 1989. "Formative assessment and the design of instructional systems". Instructional Science 18(2): 119-144.

Scriven, M. 1967. "The Methodology of Evaluation." In Perspectives of Curriculum Evaluation, edited by R.W. Tyler, R.M. Gagné, and M. Scriven, 39-83. Chicago: Rand McNally.

Sendziuk, P. 2010. "Sink or Swim? Improving Student Learning through Feedback and SelfAssessment". International Journal of Teaching and Learning in Higher Education 22(3): 320-330.

Taras, M. 2005. "Assessment-summative and formative-some theoretical reflections". British Journal of Educational Studies 53(4): 466-478.

Tuck, J. 2017. Academics engaging with student writing: Working at the higher education textface. Abingdon: Routledge.

Whitelegg, D. 2002. "Breaking the feedback loop: problems with anonymous assessment". Planet, 5(1): 7-8.

Winstone, N.E. 2019. "Facilitating students' use of feedback: Capturing and tracking impact using digital tools". In The impact of feedback in higher education: Improving assessment outcomes for learners, edited by M. Henderson, R. Ajjawi, D. Boud, and E. Molloy, 225-242. London: Palgrave.

Winstone, N., and D. Boud. 2019. "Exploring cultures of feedback practice: the adoption of learning-focused feedback practices in the UK and Australia". Higher Education Research and Development 38(2): 411-425.

Winstone, N., and D. Carless. 2019. Designing effective feedback processes in higher education: A learning-focused approach. Abingdon: Routledge.

Winstone, N.E., R.A. Nash, J. Rowntree, and R. Menezes. 2016. "What do students want most from written feedback information? Distinguishing necessities from luxuries using a budgeting methodology". Assessment and Evaluation in Higher Education 41(8): 1237-1253. 
Winstone, N.E., R.A. Nash, J. Rowntree, and M. Parker. 2017a. "“It'd be useful, but I wouldn't use it': barriers to university students' feedback seeking and recipience". Studies in Higher Education 42(11): 2026-2041.

Winstone, N.E., R.A. Nash, M. Parker, and J. Rowntree. 2017b. 'Supporting learners' agentic engagement with feedback: A systematic review and a taxonomy of recipience processes". Educational Psychologist 52(1): 17-37.

Yang, M., and D. Carless. 2013. "The feedback triangle and the enhancement of dialogic feedback processes". Teaching in Higher Education 18(3): 285-297. 